\title{
Augmented Reality Ground Marshall Airplane Berbasis Android
}

\author{
Tulus Wahyuno ${ }^{1)}$; Iwan Ady Prabowo ${ }^{2)}$; Dwi Remawati ${ }^{3)}$ \\ 1, 2,3) Program Studi Teknik Informatika, STMIK Sinar Nusantara Surakarta \\ 1) tuluswahyuno@gmail.com, ${ }^{2)}$ iwanadyp@sinus.ac.id, ${ }^{3)}$ dwirema@sinus.ac.id
}

\begin{abstract}
A marshall ground is demanded to be able to work efficiently, quickly, and precisely to give direction to the pilot. Before the aircraft is parked on the destination runway, marshall ground must ensure the sterile field conditions. Pradita Dirgantara High School students were given this material to equip aerospace insight. Augmented Reality is a technology that expands physical world by adding layers of digital information into it. The purpose of this study is to apply Augmented Reality Technology for marshall ground as a learning medium for Pradita Dirgantara High School students. The results of this study are applications for learning media. Based on a questionnaire distributed to respondents after testing the application, the application is the best application with an average value of $92.7 \%$.
\end{abstract}

Keyword : Ground Marshall, Augmented reality, Marshalling Signals, Learning Media

\section{PENDAHULUAN}

SMA Pradita Dirgantara merupakan sekolah unggulan yang mempunyai karakter kedirgantaraan, siswa diberikan pengetahuan kedirgantaraan diantaranya adalah pesawat terbang dan komponen yang ada didalamnya salah satunya adalah ground marshall.

Saat ini guru dalam menyampaikan materi tentang ground marshall masih menggunakan cara yang kovensional, seperti dengan menggunakan slide power point, buku, dan modul pembelajaran, guru belum menggunakan metode yang menggunakan teknologi terbaru sehingga siswa tidak ada media simulasi lain yang dapat digunakan untuk menambah pengetahuannya.

Dengan adanya kemajuan teknologi, pemanfaatan Augmented reality merupakan metode pembelajaran baru yang inovatif, kreatif, interaktif dan komunikatif, gambar dan alat peraga yang biasanya digunakan oleh guru dapat digantikan dengan model yang ditampilkan secara virtual menggunakan perangkat android. Augmented reality adalah penggabungan benda-benda nyata dan maya di lingkungan nyata, berjalan secara interaktif dalam waktu nyata, dan terdapat integrasi antar benda dalam tiga dimensi, yaitu benda maya terintegrasi dalam dunia nyata.[1]

Tujuan dalam paper ini adalah untuk merancang dan membangun aplikasi agar pada saat pembelajaran ground marshall materi ini menjadi materi yang menarik bagi siswa, karena media yang digunakan adalah media pembelajaran yang baru dan lebih menarik yaitu dengan menggunakan augmented reality.

\section{TINJAUAN PUSTAKA}

Penelitian tentang augmented reality telah banyak dilakukan, diantaranya [1], [2],[3], [4], [5], [6], [7] dan [8]. Sedangkan penelitian yang terkait dengan media pembelajaran sebagai penunjang Kurikulum K13 dilakukan oleh M. Mantasia and $\mathrm{H}$. Jaya [2], terkait dengan Media Pembelajaran untuk Hardware Komputer oleh A. Wiharto dan C. Budihartanti [3] dan Media Pembelajaran untuk Sel penyusun Jaringan dilakukan oleh E.N. Romadhon, H. Anra dan H.S. Pratiwi [4].

Sedangkan penelitian terkait dengan menggunakan Marker Base Tracking dilakukan oleh S. D.Y Kusuma [5]. Pada penelitian tersebut yang digunakan adalah Markerless Augmented Reality, namun untuk marker yang digunakan adalah marker yang telah diregistrasikan pada Vuforia, agar dapat dikenal oleh AR devices. Jenis marker pada vuforia yaitu bersifat markerless, artinya bentuk marker yang digunakan dapat berupa gambar bebas namun harus sudah diregistrasikan di situs resmi vuforia.

Penelitian yang dilakukan $\mathrm{A}$. Wiharto dan C. Budihartanti [3] menggunakan Algoritma FAST Corner Detection (deteksi sudut) merupakan suatu pendekatan yang digunakan pada suatu sistem visi komputer untuk mendeteksi sudut-sudut dari suatu obyek. Nama lain Corner Detection adalah Interest Point Detection. Pendekatan ini biasanya digunakan untuk mendeteksi suatu obyek untuk menentukan kekhususan pada suatu 
obyek misal dari segi bentuk obyek dan pelacakan obyek.

Kemudian pada tahun 2018 Yudha Akbar Pramana, Komang Candra Brata, dan Adam Hendra Brata [1], Tim peneliti memperkenalkan Benda di Museum Blambangan Banyuwangi berbentuk 3D. Aplikasi ini menggunakan marker yang diaplikasikan dalam FaceAr dan LeafletAr.

Hasil pengujian aplikasi Augmented Reality untuk media pembelajaran penyusunan jaringan [4] menyatakan bahwa Pengujian black-box pada fitur virtual Button berdasarkan marker dari katalog. Virtual button muncul dan berfungsi dengan baik apabila marker terdeteksi dengan baik. Untuk persentase kenaikan nilai dari Pre Test ke Post Test, siswa yang belajar menggunakan buku mata pelajaran mendapat kenaikan sebesar $18,77 \%$, sedangkan untuk kelompok siswa yang belajar menggunakan aplikasi AR'SGM mendapat kenaikan sebesar $23,5 \%$.

Pada penelitian ini, lebih memfokuskan pada penggunaan Augmented Reality berbasis Android untuk pembelajaran tentang Ground Marshall Airplane, proses pembuatan sampai dengan uji cobanya.

\section{METODE PENELITIAN}

\subsection{Studi Literatur}

Pada tahap ini, penulis mencari bahanbahan pustaka yang berhubungan dengan prototype, visual, desain media informasi, dll. Analisa masalah yang terdiri dari studi literature, bertujuan untuk mempelajari kebutuhan dari masyarakat, selanjutnya dengan cara melakukan wawancara kepada pihak SMA Pradita Dirgantara.

\subsection{Studi Pustaka}

Pada metode ini penulis melakukan pencarian sumber referensi jurnal yang berhubungan dengan relevan dengan masalah pada penelitian.

\subsection{Pengembangan Aplikasi}

Pengembangan aplikasi ini menggunakan prosedur pengembangan program multimedia Augmented Reality Ground Marshall Airplane di SMA Pradita Dirgantara. Berikut tahapantahapan dari prosedur pengembangan aplikasi Augmented Reality Ground Marshall Airplane di SMA Pradita Dirgantara adalah sebagai berikut:

\section{Merancang Ide Konsep Aplikasi}

Langkah awal membangun aplikasi ini adalah merancang konsep dari aplikasi. Pada langkah ini penulis melakukan pengamatan bagaimana seorang Ground Marshall dapat memandu Pilot untuk memarkir pesawat serta bagaimana menjawab rumusan masalah yang telah dibuat sebelumnya.

\section{Skenario / Alur Materi}

Setelah tema dan konsep ditemukan, kemudian membuat skenario atau membuat alur cerita.

\section{Membuat Sketsa Model Objek Marshalling Signal}

Setelah alur cerita ditentukan kemudian membuat sketsa atau rancangan model dari tipe-tipe Marshalling Signal yang akan dijadikan sebagai objek simulasi.

\section{Storyboard}

Pada tahap ini merupakan penyusunan sketsa gambar dan teks secara berurutan setiap halaman aplikasi sesuai dengan skenario atau alur.

\section{Modelling}

Pada tahap ini dilakukan pembuatan objek 2D sesuai sketsa / rancangan sebelumnya. Pembuatan objek 2D dirancang dengan menggunakan software CorelDraw dan unity $3 D$ untuk desain aplikasi.

\section{Aplikasi AR}

Setelah objek 2D selesai dibuat kemudian di export kedalam aplikasi AR (Unity 3D). Pada tahap ini menggunakan software Unity $3 D$.

\section{Testing}

Pada langkah ini dilakukan uji coba aplikasi AR setelah di-export / render. Jika masih terdapat error, akan dilakukan perbaikan dan dilakukan testing lagi sampai tidak terdapat error pada program.

\section{Hasil}

Setelah melalui uji testing kemudian aplikasi AR siap digunakan, aplikasi tersebut di uji coba dengan menggunakan smartphone android.

\section{Pengujian Black Box}

Pengujian berikutnya adalah pengujian dengan metode black box. Pengujian black box adalah pengujian aspek fundamental sistem tanpa memperhatikan struktur logika internal perangkat lunak. 


\section{Pengujian Kelayakan Sistem}

Merupakan pengujian yang menentukan layak tidaknya suatu aplikasi diterjunkan.

\section{HASIL DAN PEMBAHASAN}

\subsection{Perancangan Aplikasi}

\section{A. Alur Kerja Augmented Reality}

Alur kerja augmented reality ground marshall airplane yang dibuat adalah seperti Gambar 1.

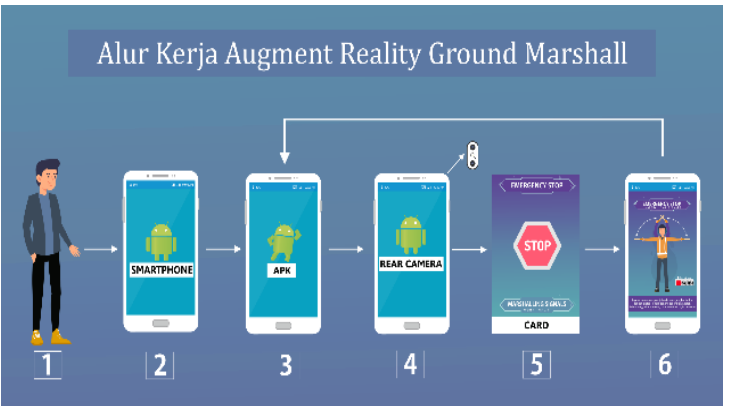

Gambar 1. Alur kerja augmented reality ground marshall airplane

Penjelasan dari alur kerja diatas adalah sebagai berikut:

1. User mulai berinteraksi langsung dengan smartphone dan menginstal aplikasi (.apk) agar aplikasi dapat digunakan.

2. Smartphone mulai mengakses aplikasi dan user disajikan tampilan dalam aplikasi untuk mulai menggunakannya.

3. Aplikasi akan mengakses kamera belakang smartphone android yang selanjutnya akan digunakan untuk deteksi marker.

4. Kamera smartphone akan berinteraksi dengan kartu dan mulai mendeteksi marker yang terdapat dalam kartu tersebut.

5. Kartu Augmented reality merupakan object yang akan memberikan informasi bagi user jika marker terdeteksi.

6. Setelah kartu di scan oleh kamera smartphone dan marker terdeteksi maka akan menampilkan informasi dari kartu tersebut, setelah itu jika ditekan tombol kembali user akan kembali berinteraksi dengan aplikasi untuk memilih AR yang lainya.

\section{B. Flowchart Pengenalan Pola}

Langkah-langkah diatas digambarkan kedalam sebuah flowchart seperti Gambar 2 dibawah ini.

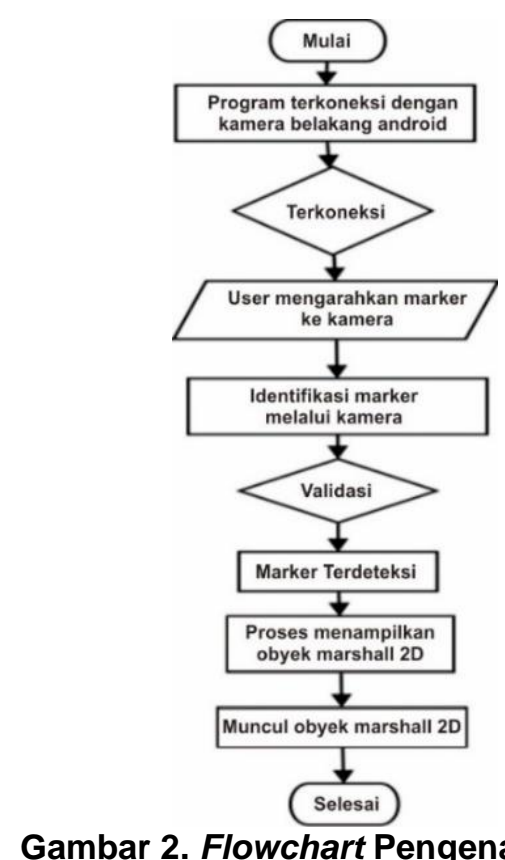

Gambar 2. Flowchart Pengenalan Pola

Aplikasi ini bersifat stand alone atau dengan kata lain berdiri sendiri, dimana tidak ada interaksi client-server sehingga dalam proses menjalankannya hanya membutuhkan satu user saja.

\section{Flowchart Aplikasi}

Flowchart dari aplikasi yang dibuat adalah seperti Gambar 3.

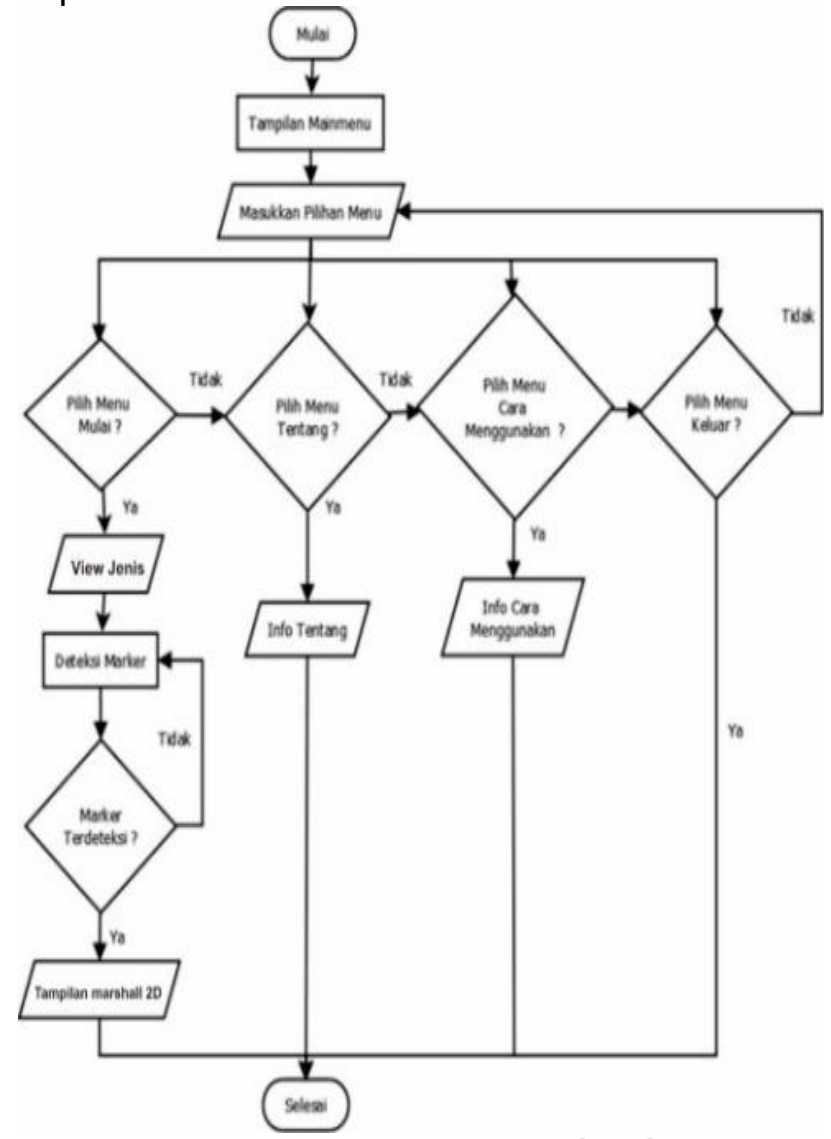

Gambar 3. Flowchart Aplikasi 


\section{Perancangan Marker}

Dalam sistem ini terdapat inputan berupa pola (marker). Marker inilah yang akan dideteksi oleh kamera belakang smartphone android dan bila terdeteksi maka akan menampilkan objek marshall 2D. Marker yang digunakan dibuat dengan aplikasi CorelDraw 2019, dan nantinya marker ini dalam bentuk kartu seperti Gambar 4.

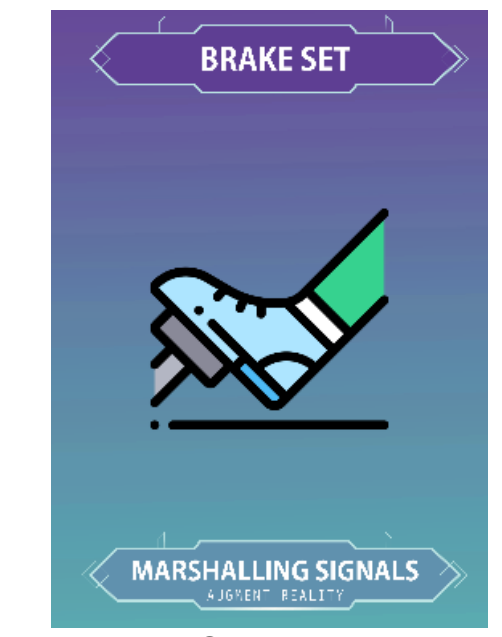

Gambar 4. Sampel Pola Marker

\section{E. Mekanisme Pembacaan Marker}

Pada umumnya sistem pendeteksi akan mengidentifikasi dengan cara membandingkan gambar tersegmentasi dengan marker template. Sebuah marker template merupakan gambar sample dari marker. Selama proses identifikasi, aplikasi akan mencocokan marker yang terdeteksi terhadap setiap template dan hasilnya akan menentukan sebuah indentitas.

\section{F. Perangkat Pembuatan Aplikasi}

Pada tahap pembuatan aplikasi Augmented Reality dilakukan dengan menggunakan beberapa software sebagai berikut :
a. Unity 3D
b. Vuforia
c. CorelDraw

Sedangkan perangkat keras yang digunakan memiliki spesifikasi sebagai berikut :
a. Prosessor Intel(R) Core(TIM i7-8750H CPU@2.20GHz2.21 GHz
b. RAM $8 \mathrm{~GB}$

\section{G. Pengujian}
Teknik pengujian yang digunakan adalah Blackbox testing yaitu pengujian yang menunjukkan tentang cara beroprasinya sebuah aplikasi. Blackbox testing ini

memfokuskan pada keperluan fungsional dari sebuah software. Pengujian aplikasi dilakukan dengan metode Black-box untuk mengetahui apakah semua fungsi berjalan sesuai.

\subsection{Hasil Implementasi}

Hasil dari aplikasi Augmented Reality ini adalah sebagai berikut :

\section{A. Splash screen}

Splash screen merupakan tampilan sambutan yang berisi tentang nama produk aplikasi. Dalam aplikasi ini terdapat efek, efek yang digunakan dalam aplikasi ini adalah fade in, efek ini membuat tampilan splash screen terlihat halus. Gambar halaman Splash screen dapat dilihat pada Gambar 5.

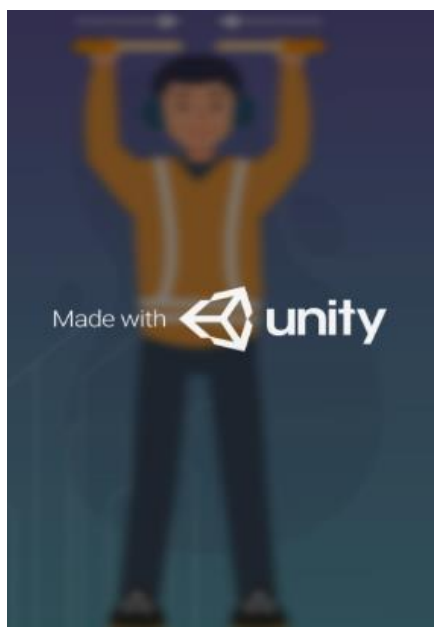

Gambar 5. Tampilan Splash Screen Aplikasi

\section{B. Mainmenu}

Mainmenu merupakan tampilan yang langsung dituju oleh Splash screen. Dalam aplikasi ini terdapat 3 tombol utama, yakni tombol Mulai untuk menuju ke halaman utama, tombol Tentang untuk menampilkan deskripsi aplikasi, dan yang ketiga adalah tombol Exit untuk keluar aplikasi. Gambar halaman Mainmenu dapat dilihat pada Gambar 6. 


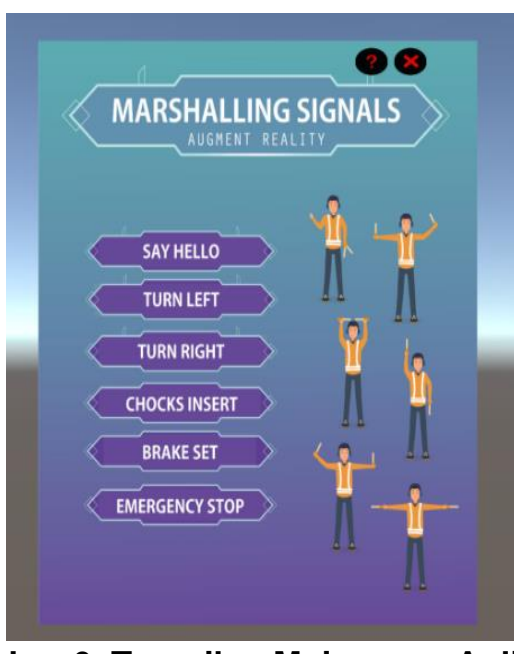

Gambar 6. Tampilan Mainmenu Aplikasi

\section{Menu Tentang}

Menu Tentang merupakan tampilan yang menampilkan tentang deskripsi dari aplikasi. Tedapat tombol Home yang digunakan untuk mengakses ke halaman sebelumnya yakni halaman Mainmenu. Gambar halaman tentang dapat dilihat pada Gambar 7.

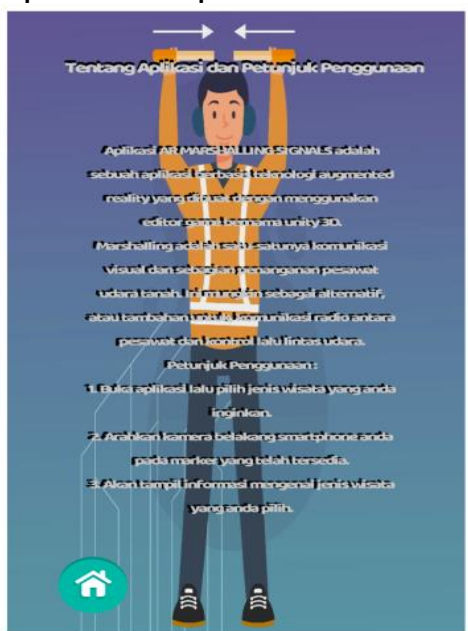

\section{Gambar 7. Tampilan Menu Tentang Aplikasi}

\section{Menu ViewObyek}

Menu View Obyek merupakan tampilan yang menampilkan model obyek marshall yang nantinya akan dipilih oleh pengguna. Terdapat tombol Home yang digunakan untuk mengakses ke halaman Mainmenu Gambar halaman View obyek dapat dilihat pada Gambar 8.

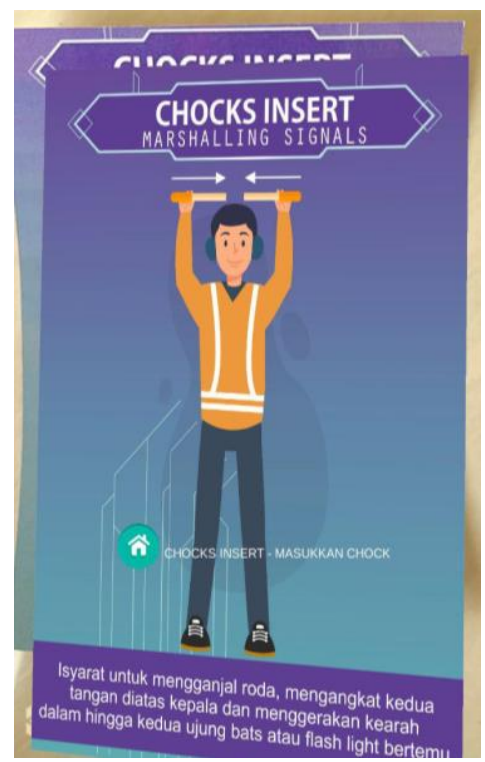

Gambar 8. Tampilan Menu View Model Aplikasi

\subsection{Pengujian Blackbox}

Teknik pengujian yang digunakan adalah Blackbox testing yaitu pengujian yang menunjukkan tentang cara beroperasinya sebuah aplikasi. Blackbox testing ini memfokuskan pada keperluan fungsional dari sebuah software. Pengujian aplikasi dilakukan dengan metode Black-box untuk mengetahui apakah semua fungsi berjalan sesuai[9]. Tabel black-box dapat dilihat pada Tabel 1-5 dibawah ini.

Tabel 1. Hasil Uji Black-box Splash Screen

\begin{tabular}{|c|c|c|}
\hline Halaman & Yang diuji & Hasil \\
\hline $\begin{array}{c}\text { Tampilan } \\
\text { splash } \\
\text { screen }\end{array}$ & $\begin{array}{c}\text { Klik Aplikasi } \\
\text { pada handphone }\end{array}$ & $\begin{array}{c}\text { Berjalan } \\
\text { dengan baik }\end{array}$ \\
\hline
\end{tabular}

Tabel 2. Hasil Uji Black-box Mainmenu

\begin{tabular}{|c|c|c|}
\hline Halaman & Yang diuji & Hasil \\
\hline $\begin{array}{c}\text { Tombol } \\
\text { "Tentang" } \\
\text { Mainmenu }\end{array}$ & $\begin{array}{c}\text { Klik tombol } \\
\text { "Tentang" } \\
\text { mainmenu }\end{array}$ & $\begin{array}{c}\text { Berjalan } \\
\text { dengan baik }\end{array}$ \\
\hline $\begin{array}{c}\text { Tombol } \\
\text { "Mulai" } \\
\text { mainmenu }\end{array}$ & $\begin{array}{c}\text { Klik tombol } \\
\text { "Mulai" pada } \\
\text { handphone }\end{array}$ & $\begin{array}{c}\text { Berjalan } \\
\text { dengan baik }\end{array}$ \\
\hline $\begin{array}{c}\text { Tombol } \\
\text { "Exif" } \\
\text { Mainmenu }\end{array}$ & $\begin{array}{c}\text { Klik tombol } \\
\text { "Exif" } \\
\text { mainmenu }\end{array}$ & $\begin{array}{c}\text { Berjalan } \\
\text { dengan baik }\end{array}$ \\
\hline \multicolumn{3}{|c}{} \\
\hline
\end{tabular}

Tabel 3. Hasil Uji Black-box Menu Tentang

\begin{tabular}{|c|c|c|}
\hline Halaman & Yang diuji & Hasil \\
\hline $\begin{array}{c}\text { Tombol } \\
\text { "Tentang" }\end{array}$ & $\begin{array}{c}\text { Klik tombol } \\
\text { "Tentang" }\end{array}$ & $\begin{array}{c}\text { Berjalan } \\
\text { dengan baik }\end{array}$ \\
\hline $\begin{array}{c}\text { Tombol } \\
\text { "Home" }\end{array}$ & $\begin{array}{c}\text { Klik tombol } \\
\text { "Home" }\end{array}$ & $\begin{array}{c}\text { Berjalan } \\
\text { dengan baik }\end{array}$ \\
\hline
\end{tabular}


Tabel 4. Hasil Uji Black-box Menu View Model

\begin{tabular}{|c|c|c|}
\hline Halaman & Yang diuji & Hasil \\
\hline $\begin{array}{c}\text { Tombol } \\
\text { "View } \\
\text { Model" }\end{array}$ & $\begin{array}{c}\text { Klik tombol } \\
\text { "View obyek" }\end{array}$ & $\begin{array}{c}\text { Berjalan } \\
\text { dengan baik }\end{array}$ \\
\hline $\begin{array}{c}\text { Tombol } \\
\text { Pilih } \\
\text { marshall }\end{array}$ & $\begin{array}{c}\text { Klik tombol Pilih } \\
\text { marshall }\end{array}$ & $\begin{array}{c}\text { Berjalan } \\
\text { dengan baik }\end{array}$ \\
\hline $\begin{array}{c}\text { Tombol } \\
\text { "Home" }\end{array}$ & $\begin{array}{c}\text { Klik tombol } \\
\text { "Home" }\end{array}$ & $\begin{array}{c}\text { Berjalan } \\
\text { dengan baik }\end{array}$ \\
\hline $\begin{array}{c}\text { Tombol } \\
\text { "Youtube" }\end{array}$ & $\begin{array}{c}\text { Klik tombol } \\
\text { "Youtube" }\end{array}$ & $\begin{array}{c}\text { Berjalan } \\
\text { dengan baik }\end{array}$ \\
\hline
\end{tabular}

Tabel 5. Hasil Uji Black-box Exit

\begin{tabular}{|c|c|c|}
\hline Halaman & Yang diuji & Hasil \\
\hline $\begin{array}{c}\text { Tombol } \\
\text { "Exit" }\end{array}$ & Klik tombol "Exit" & $\begin{array}{c}\text { Berjalan } \\
\text { dengan baik }\end{array}$ \\
\hline $\begin{array}{c}\text { Tombol } \\
\text { "Yes" }\end{array}$ & Klik tombol "Yes" & $\begin{array}{c}\text { Berjalan } \\
\text { dengan baik }\end{array}$ \\
\hline $\begin{array}{c}\text { Tombol } \\
\text { "No" }\end{array}$ & Klik tombol "No" & $\begin{array}{c}\text { Berjalan } \\
\text { dengan baik }\end{array}$ \\
\hline
\end{tabular}

Berdasarkan pengujian Black Box yang telah dilakukan didapat hasil yang ditunjukan pada tabel 1 - 5 yang menunjukan bahwa semua menu dapat berjalan dengan baik. Begitupun semua menu pilihan yang ada pada menu Informasi yang meliputi 6 marshalling signals semua berjalan dengan baik.

\section{Pengujian Kelayakan Sistem}

Pengujian selanjutnya dilakukan dengan cara memberikan angket atau kuisioner kepada pengguna untuk melakukan penilaian. Dalam penelitian ini responden dari kuisioner adalah siswa berjumlah 27 siswa dan 3 guru. Angket kepuasan pengguna yang telah diisi siswa dan guru diolah dengan mengggunakan skala litert dengan rentang skala 1 sampai 3 . Artinya jika tingkat kepuasan cenderung lebih baik dari sebelum menggunakan aplikasi maka dinyatakan dengan skala 3. Jika pengguna merasa tingkat kepuasan masih sama saja maka dinyatakan dengan skala 2 . Dan jika pengguna merasa tingkat kepuasan lebih buruk dari sebelum menggunakan aplikasi maka dinyatakan dengan skala 1 . Tabel 6 merupakan Tabel Skala Pengukuran :

\section{Tabel 6. Skala Pengukuran}

\begin{tabular}{|c|c|}
\hline No & Kategori \\
\hline 1 & Sangat Baik (SB) \\
\hline 2 & Baik (B) \\
\hline 3 & Tidak Baik (TB) \\
\hline
\end{tabular}

Perhitungan menggunakan skala likert akan dijelaskan di bawah ini dengan salah satu contoh pertanyaan :

\section{Apakah aplikasi mudah digunakan ?}

$>$ Hasil Jawaban

1. Sangat Baik (SB) = 6

orang

2. Baik $(\mathrm{B}) \quad=\quad 7$

orang

3. Tidak Baik (TB) = 0 orang

$>$ Kemudian dari data yang didapat diatas kemudian diolah dengan cara mengkalikan setiap point jawaban dengan bobot atau skala yang sudah ditentukan.

1. Responden yang menjawab Sangat Baik (3) $=6 \times 3=18$

2. Responden yang menjawab Baik $(2)=7 \times 2=14$

3. Responden yang menjawab Tidak Baik $(1)=0 \times 1=0$

Total : $18+14+0=32$

$>$ Kemudian ditentukan skor tertinggi dengan nilai $(X)$ dan skor terendah dengan nilai $(Y)$.

$X=$ Skor tertinggi $x$ jumlah responden (angka tertinggi adalah 3 ).

$\mathrm{Y}=$ Skor terendah $\mathrm{x}$ jumlah responden (angka terendah adalah 1).

$\mathrm{X}=\mathrm{SB}=3 \times 13=39$

$Y=T B=1 \times 13=13$

Rumus Index \% = Total Skor $/$ X x 100

$=32 / 39 \times 100$

$=82,051 \%$

Tabel 7. Presentase Nilai

\begin{tabular}{|l|l|}
\hline \multicolumn{1}{|c|}{ Jawaban } & \multicolumn{1}{c|}{ Keterangan } \\
\hline $0 \%-32,99 \%$ & TB (Tidak Baik) \\
\hline $33 \%-65,99 \%$ & B (Baik) \\
\hline $66 \%-100 \%$ & SB (Sangat Baik) \\
\hline
\end{tabular}

Dari hasil pada Tabel 7 diatas dapat disimpulkan bahwa hasil jawaban yang dihitung dengan rumus index bernilai 82,051 $\%$. Berarti pertanyaan "Aplikasi Mudah Digunakan" termasuk dalam kategori SETUJU.

Pengujian selanjutnya dilakukan dengan cara memberikan angket atau kuisioner kepada pengguna untuk melakukan penilaian yaitu perbandingan antara metode kovensional dan dengan menggunakan media pembelajaran berbasis aplikasi. Dalam penelitian ini responden dari kuisioner adalah 
27 orang siswa dan 3 orang guru. Angket kepuasan pengguna yang telah diisi siswa dan guru diolah dengan mengggunakan Skala Litert dengan rentang skala 1 sampai 3 . Gambar 9 merupakan Grafik Presentase angket kuisioner.

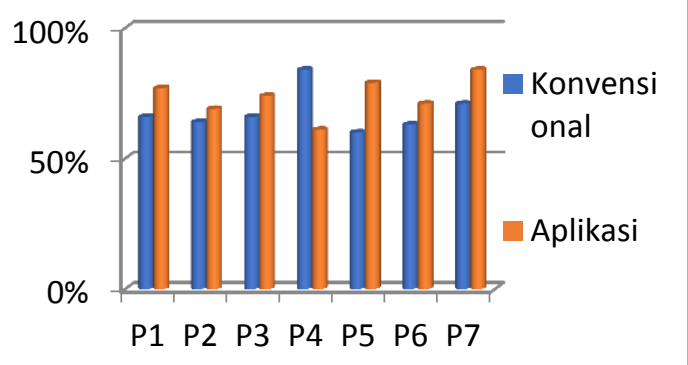

Gambar 9. Grafik Presentase Angket Kuisioner

Hasil rata-rata hasil presentase penggunaan metode konvensional adalah $=(66 \%+64 \%+$ $66 \%+84 \%+60 \%+63 \%+71 \%): 7=67.8$ $\%$.

Hasil rata-rata dari Presentase Penggunaan Metode Pembelajaran dengan Aplikasi adalah $=(77 \%+69 \%+74 \%+61 \%+79 \%+71 \%+$ $84 \%): 7=73.7 \%$.

\section{Analisa Hasil Pengujian Kelayakan Sistem}

Dari hasil angket yang telah diberikan pada 30 responden dari 3 guru dan 27 siswa, dapat diketahui bahwa secara umum berdasarkan analisis angket yang diberikan kepada responden, metode pembelajaran dengan menggunakan aplikasi adalah metode yang paling digemari oleh mayoritas responden dengan rata-rata $73.7 \%$ dibandingkan dengan metode konvensional yang hanya mendapatkan rata-rata $67.8 \%$. Dari jawaban yang diberikan oleh responden maka terdapat banyak hal yang harus ditulis dalam aplikasi tersebut. Menurut siswa, metode pembelajaran dengan menggunakan aplikasi ini memiliki kelebihan sebagai berikut, dapat berfungsi sebagai media simulasi marshalling signals yang interaktif, mudah dalam penggunaan, mendukung penggunaan teknologi, mempercepat proses informasi dan lebih praktis. Tetapi aplikasi ini juga masih memiliki kekurangan yaitu hanya terbatas pada siswa yang memiliki smartphone android saja.

Berdasarkan hasil pengujian yang telah dilaksanakan dapat ditarik kesimpulan bahwa metode pembelajaran dengan menggunakan aplikasi adalah metode yang paling digemari oleh mayoritas responden dengan rata-rata $73.7 \%$ dibandingkan dengan metode konvensional yang hanya mendapatkan ratarata $67.8 \%$.

\section{PENUTUP}

\subsection{Kesimpulan}

Kesimpulan yang dapat diambil adalah telah berhasil membuat sebuah aplikasi Marshalling Signals dengan teknologi Augmented Reality berbasis android yang merupakan metode pembelajaran baru yang inovatif dan kreatif.

\subsection{Saran}

Saran untuk pengembangan aplikasi agar lebih baik lagi adalah sebagai berikut:

1. Koleksi kartu marshalling signals lebih diperbanyak lagi, agar semakin lebih banyak pilihan yang disediakan.

2. Memberikan audio narasi dari gerakangerakan marshalling signals, sehingga selain melihat secara visual juga dapat mendengarkan audio narasinya.

\section{DAFTAR PUSTAKA}

[1] Y. A. Pramana, K. C. Brata, and A. H. Brata, "Pembangunan Aplikasi Augmented Reality untuk Pengenalan Benda di Museum Berbasis Android ( Studi Kasus: Museum Blambangan Banyuwangi )," vol. 2, no. 5, pp. 20342042, 2018.

[2] M. Mantasia and $\mathrm{H}$. Jaya, "Pengembangan Teknologi Augmented Reality Sebagai Penguatan Dan Penunjang Metode Pembelajaran Di Smk Untuk Implementasi Kurikulum 2013," J. Pendidik. Vokasi, vol. 6, no. 3, p. 281, 2016.

[3] A. Wiharto and C. Budihartanti, "Aplikasi Mobile Augmented Reality Sebagai Media Pembelajaran Pengenalan Hardware Komputer Berbasis Android," PROSISKO J. Pengemb. Ris. dan Obs. Sist. Komput., vol. 4, no. 2, pp. 17-24, 2017.

[4] E. N. Romadhon, H. Anra, and H. S. Pratiwi, "Penerapan Augmented Reality Berbasis android Sebagai Media Pembelajaran Sel Penyusun Jaringan $p$ ada Sistem Gerak d alam Mata Pelajaran Biologi ( Studi Kasus: S MA Negeri 7 Pontianak )," J. Sist. dan Teknol. Inf., vol. 5, no. 2, pp. 89-92, 2017.

[5] S. D. Y. Kusuma, "Perancangan Aplikasi Augmented Reality Pembelajaran Tata Surya dengan Menggunakan Marker 
Based Tracking," J. Inform. Univ. Pamulang, vol. 3, no. 1, p. 33, 2018.

[6] M. Muntahanah, R. Toyib, and M. Ansyori, "Penerapan Teknologi Augmented Reality Pada Katalog Rumah Berbasis Android (Studi Kasus Pt. Jashando Han Saputra)," Pseudocode, vol. 4, no. 1, pp. 81-89, 2017.

[7] U. Muhayat, W. Wahyudi, H. Wibawanto, and W. Hardyanto, "Pengembangan Media Edukatif Berbasis Augmented Reality untuk Desain Interior dan Eksterior," Innov. J. Curric. Educ. Technol., vol. 6, no. 2, pp. 39-48, 2017.

[8] P. Studi, T. Informatika, F. Teknik, and U. Tanjungpura, "Implementasi Augmented Reality Pada Brosur Teknik Informatika Universitas," vol. 1, no. 1, pp. 1-6, 2016. 